\title{
AN APPRAISAL OF ALBERTA'S NEW PRORATIONING SCHEME*
}

\begin{abstract}
Alberta's new prorationing scheme was released by the Oil and Gas Conservation Board in July of 1964, and will be fully implemented on the 1st day of May, 1969. This article discusses the evolution and implementation of the proration concept, explores the necessity for proration and analyzes the principles upon which a sound proration scheme must be based. The author compares the new proration plan with the Board's former plan and concludes that the new plan is a novel approach to proration which, upon full implementation, may not entirely fulfil the prime functions of a proration scheme, which is the prevention of waste and the protection of correlative rights.
\end{abstract}

\section{A. INTRODUCTION}

In July, 1964, the Oil and Gas Conservation Board of Alberta (hereinafter referred to as "the Board"), after considering submissions" made to it at a public hearing, published its report entitled "Report and Decision on Review of Plan for Proration of Oil to Market Demand"." This report introduced to Alberta a new method of prorationing production of oil to market demand. ${ }^{3}$ The new plan retained many of the policies with respect to prorationing formulated by the Board since its inception in 1938, but incorporated several fundamental changes which, when fully implemented, will result in an entirely different distribution of the market demand among the wells in the Province. The most significant changes in terms of the amount of production that may be taken from a well are:

(1) the change from an economic allowance concept to a floor allowance principle. ${ }^{4}$

(2) the initial distribution of the market demand on the basis of the oil reserves of each pool rather than on the basis of the economic allowances 5 within a pool.

(3) the introduction of a production spacing unit (PSU) ${ }^{\circ}$ as distinguished from a drilling spacing unit $(D S U)^{T}$ to be used as a parameter in establishing the allowable for a well.

- This paper was prepared by STEVE VAVRA of the 1967 graduating class of the Faculty of Law, University of Alberta, for presentation to the Oil and Gas Seminar at the University of Alberta in February, 1967. Mr. Vavra holds a B.Sc. Degree in Chemical Engineering and was employed by the Oil and Gas Conservation Board in various cal Engineering and was employed by the Oil and Gas Conservation Board in various the study of Law. the study of Law.

1 Infra, n. 2, at 4.

3 Oil and Gas Conservation Act. S.A. 1957, c. 63, s. 2(i), defines "market demand" as the amount of ofl or gas reasonably needed for current consumption, use, storage and working stocks within and outside the Province.

4 The distinction between an economic allowance and a floor allowance is best $11-$ lustrated by the Board's definitions of these terms, supra, n. 2, at 9:

Minimum allowance-A basic allowance or a floor allowance. That part of a well's inimum allowance-A basic allowance or a floor allowance. That part of a well s allowable which does not vary from month to month and which the well shall receive unaffected by variations in market demand as long as the

Basic allowance-The minimum allowance of a well in a system whereby the aggregate of all minimum allowances is subtracted from the provincial allowable and the balance of the market demand is allocated and distributed according to other factors.

Floor allowance-The minimum allowance of a well in a system whereby all of the provincial allowable is allocated and distributed according to proration factors, subject to adjustment so that every qualified well may recelve its minimum allowance.

Economic allowance-The basic allowance used in the present plan more or less reflecting the cost of operating a well, the cost of completing a well, the cost of drilling $a$ well or $a$ combination of them. The present plan provides for an of drilling a well or a combinatlon initial economic airswance rears more or less of a pool's production and after apply during the first seven years more or less of a pool's production and after that an operating economic allowance it.

s Id., as to the definition of an "Economic Allowance."

b Oil and Gas Conservation Act, s. 2 (p1), defines a production spacing unit. See

7 Id., s. 2 (ci) defines a drilling spacing unit. See S.A. 1965, c. 65, s. 2 (b). 
The purpose of this paper is to:

(1) review the evolution of the proration concept in the United States and Canada.

(2) compare the various aspects of the proration schemes adopted in the United States and Canada.

(3) decide on the principles which should govern the distibution of the market demand.

(4) compare and appraise the Board's new plan for proration with reference to established principles of proration.

(5) consider the economic effects the Board's new plan may have upon the Province and the Petroleum Industry in the Province.

(6) consider the impact the recent vast discoveries of oil in Northern Alberta may have upon the new plan together with the ultimate effect these new reserves may have upon the distribution of market demand among the developed oil pools in the Province.

While dealing with each of the above described topics, emphasis will be placed upon what the writer considers to be potential weaknesses of the new plan; however, this should not be construed as an overall condemnation of the new plan. Any criticism rendered is solely intended to be constructive in nature and should be interpreted accordingly.

\section{Development}

\section{B. EVOLUTION OF PRORATION}

Early conservation statutes regulating individual well spacing, casing design, flaring, etc., were first enacted in the United States in the states of California, Texas and Oklahoma from 1915 to 1919, but it was not until 1930-32 that some of these statutes incorporated provisions enabling the conservation authorities to limit production to the market demand of the state. The incentive for embodying such provisions arose from the need to prevent apparent surface waste resulting from open pit storage and dumping of excessive production. Later it was also realized that production at capacity was creating subsurface waste ${ }^{*}$ through excessive dissipation of reservoir energy and premature water and/or gas encroachment into the oil zone. Controlled production rates were recognized as the only means of avoiding these physical wastes of the petroleum resources of the country.

The obvious solution to the elimination of surface losses was to limit production to whatever the market for the state would bear. This meant that the market demand had to be determined in advance so that quotes or allowables ${ }^{0}$ could be established. At first this was regarded an ominous task, but with time the conservation authorities found such predictions could be made with remarkable accuracy. Today, monthly nomination hearings ${ }^{10}$ are held in most jurisdictions practicing proration to market demand.

Restricting production to the market demand did not necessarily prevent sub-surface waste caused by rapidly depleting reservoirs. In

8 Alternatively referred to as underground waste resulting when oil or gas is left unnecessarily trapped within the reservoir due to the method of production or proration. The term "allowable" as it refers to the production of oil or gas is the fixed quantity of these substances which a well is permitted to produce during a specifled period

10 Generally, monthly "nomination hearings" are held by conservation authorities to enable purchasers of crude to indicate the quantity of crude they will be requiring for the forth-coming month. 
certain pools production even at an allowable based on the market demand was excessive and would cause sub-surface waste. Consequently, it became necessary to restrict production from such pools on the basis of reservoir parameters. In this regard the "maximum efficient rate"11 (MER) formula was generally adopted as a guide to safe production rates. Although the concept evolved during the nineteen thirties, it was not truly employed in practice until World War II. At that time, demand exceeded supply and the need for proration virtually disappeared. Instead it became necessary to limit production from wells on the basis of capability. The MER formula thus became a convenient tool for ascertaining a well's and hence a reservoir's capability. ${ }^{12}$ Production was restricted accordingly.

The legal impliciation of adopting a proration concept has been to abrogate the "rule of capture". ${ }^{13}$ This rule embodied the right of a landowner to produce at capacity and the right of self-help by operators to protect their leases by offsetting wells in compliance with lease obligations. ${ }^{14} \mathrm{By}$ establishing an allowable the conservation authority precludes an owner from exercising his right to drill for and produce in accordance with the rule of capture. The onus now lies with the authority to ensure that each owner may recover his just and equitable share of the petroleum underlying his property in accordance with his share of the market demand.

The proration concept was therefore developed to fulfill two prime functions:

(1) prevent the physical waste ${ }^{1:}$ of petroleum resources of the country.

(2) enable each owner to produce his equitable share of the petroleum resources underlying his property.

Although having become more sophisticated, today's proration schemes must still fulfill these two purposes. Unless they do so, they cannot be considered compatable with a conservation approach for developing the oil resources of the country.

\section{Implementation}

There are numerous state and provincial jurisdictions in the United States and Canada which have adopted conservation legislation which includes provisions enabling the conservation body to prorate oil production to market demand. However, only a few have actually implemented such legislation. In the United States there are five states prorating production to market demand: Kansas, Louisiana, New Mexico, Oklahoma and Texas. Another six states ${ }^{26}$ have statutes empowering them to do so, and proration may be practiced to a limited extent in some of these states. In Canada only the Province of Alberta prorates oil production to market demand, while the provinces of Saskatchewan and British Columbia, which contribute significantly to the country's crude

11 Supra, n. 2, at 4, defines "MER or maximum efficient rate" as the maximum rate at which oil can be produced without avoidable underground waste.

12 A reservoir's capability would usually be determined by a summation of the individual well MER's within the reservoir.

13 Lewis and Thompson, Canadian Oil and Gas, Part II, Section 5, Item 44.

1+ Creation of drilling and/or production spacing units for wells made it impossible for a lessor to fulfill an undertaking in a lease agreement to drill an of fset well for a lessor to fulfill an undertaking in a lease agreement to drill an offset welon the leased acreage if its area was smaller than the spacing unit. Pooling pro-
visions were included in Conservation legislation to remedy this situation and have visions were included in Conservation
for the most part been successful.

15 Oll and Gas Conservatinn Ant. s. 2(f) and (u).

16 Alabama, Arizona, Florida, Michigan, North Dakota and Washington. 
oil production, operate basically on a capacity or MER concept, with some production being subject to pipeline proration in Saskatchewan.

A chronological review would put the states of Oklahoma and Texas at the forefront of jurisdictions to undertake proration to market demand. Oklahoma in 1930, partly because of earlier experience and partly because the Conservation legislation that had been enacted in 1915 seemed to have broad connotations, acted on a state wide scale by its order on June 30,1930 , effectively restricting production in the state. Texas followed suit with a similar order under its enabling legislation on August 14, 1930. Both states considered this an essential step in waste prevention and protection of property rights.

After an unsuccessful attempt by operators in Kansas in 1929 and 1930, to voluntarily restrict production from a number of pools, the state passed an Act in 1931, which patterned the Oklahoma Act. This Act, which was amended in 1933, enabled the conservation authority to restrict production within the state to market demand.

The problems of waste were as great in California as they were in the three states already mentioned; however, the statutes on the books in the 1930-32 period dealt primarily with waste occurring from individual wells and consequently the administrative agency lacked authority to regulate production on a state wide scale. A bill attempting to vest such authority with the conservation agency was defeated in 1931. The operators then worked out a voluntary program which functioned similiar to programmes adopted in states with comprehensive conservation statutes. ${ }^{1 i}$ A committee of operators would determine the market demand from the California pools for the forthcoming month and would make recommendations for production from various pools and wells. There was one vital difference however, this committee had no authority to require compliance with the recommendations. For all practical purposes California is operating under this concept to this day.

From this point on the various states adopted conservation legislation as the need arose. In most cases such legislation included the power to prorate production to market demand because it was patterned after model forms prepared by the Legal Committee of the Interstate Oil Compact Comission, ${ }^{1 \mathrm{~s}}$ which included a general provision enabling the conservation agency to restrict production to market demand.

In Alberta the need for restricting production arose in the Turner Valley field about the same time proration to market demand was initiated in the United States. Here gas production practices were grossly wasteful and an order was issued restricting production to forty per cent of potential capacity shown by the last monthy gauge. ${ }^{10}$ Several years later oil was discovered in the field, and productive capacity soon exceeded demand. An unsuccessful attempt was made to regulate production to demand by purchasers' quotas whereby the major purchasers would announce that a certain percentage of the oil taken in the previous month would be purchased the following month. It became very awkward to allocate production, particularly to new wells, as the percentages fluctuated according to the amount of oil available, refinery capacity and the demand for refined products. This condition created dissatisfaction

17 API, History of Petroleum Engineering 1144-45 (1961).

10 Beach, Alberta's Petroleum Fraternity 23 (1956). 
among the independent producers, consequently, one of the first functions of the Petroleum and Natural Gas Conservation Board ${ }^{20}$ which was formed in 1938, was to remedy this situation. The Board established a proration formula whereby each well was given a quota based on four parameters. Twenty-five per cent of the quota was based on acreage which meant that if more than one well was drilled on a forty acre parcel, a penalty was applied. Bottom hole pressure, gas-oil ratio and rate of flow were the other three parameters used to allocate production to a well, each being weighted equally."

During the Second World War, demand exceeded supply and proration became unnecessary, nevertheless the Board prescribed allowables for the Turner Valley field to prevent waste and protect correlative rights. Then in 1947, the Leduc field was discovered, and the discovery set into motion what has become the major development phase of Alberta's oil reserves. By 1949, supply again exceeded demand, and the Board.instituted a system of well acceptances": to prorate production. These created a great deal of dissatisfaction in the industry and the Board was requested to review its method for prorating production to market demand. After holding public hearings, the Board in 1950 adopted a plan which employed the "Maximum Permissive Rate" (MPR) as a proration base and a well economic allowance as an overriding factor. Except for a modification to the well economic allowance in $1957,{ }^{23}$ this plan has remained in force until the implementation of the plan which is the subject of this paper.

\section{General}

\section{COMPARISON OF PRORATION METHODS}

A comparison of the various proration schemes in use in the United States and Canada is facilitated if it is remembered that all have fundamentally the same objective, that is to distribute the market demand in the form of allowables among the wells in the state or province. The formulas and parameters that may be utilized in making this distribution, however, will vary radically from one scheme to the next. Nevertheless, it should be possible to divide any comprehensive proration scheme into three distinct steps:

(1) Determination of the market demand.

(2) Allocation of the market demand to pools.

(3) Distribution of the pool allocation among wells.

The schemes in the United States and Alberta's 1950 scheme for all practical purposes combine steps (2) and (3) into one. The net effect is that the market demand is distributed among the wells without first making an allocation to the pools. Under such a distribution the characteristics of a pool essentially become irrelevant and allocation of the market demand becomes dependant entirely upon well parameters such as depth and acreage assigned to the well. A classic example of the latter is the economic allowance ${ }^{24}$ which was entirely a function of drilling, completion and operating costs of a well.

\footnotetext{
20 The Petroleum and Natural Gas Conservation Board was renemed the Oil and Gas Conservation Board on July 1, 1957.

21 Infra, n. 19, at 24.

22 Employing the sime parameters as the formula adopted in 1938.

23 Oil and Gas Conservation Board. Letter to all operators re: Proration Plan and the Economic Allowance, August 30, 1957.

24 Supra, n. 5.
} 
Some proration schemes endeavour to compensate for omitting the second step by providing that some portion of the market demand would be distributed on the basis of pool parameters. Under Alberta's 1950 plan this was accomplished by distributing the residual market demand ${ }^{2 \pi}$ among the pools in the province in proportion to their productivity, which was simply an aggregate of the individual well Maximum Permissible Rates"i (MPR's) within the pool. However, since the residual market demand constituted only a small fraction ${ }^{2 i}$ of the market demand, the practical effects of such an allocation were minimal.

The Board's 1964 plan for proration not only places more emphasis on pool parameters but also readily lends itself to division into the three steps. Firstly, it requires that the market demand be determined at monthly nomination hearings. Secondly, it provides for the allocation of the market demand among the pools in the province in proportion to the reserves in each pool. Finally, it specifies that the pool allocation be distributed among the wells in the pool on the basis of acreage and a recovery factor modifier." As such the Board's new plan satisfies the requirements of a logical proration scheme much better than any other known scheme in practice.

\section{U.S. Schemes}

A recent paper ${ }^{29}$ published in the Journal of Petroleum Technology makes an excellent comparison of oil proration methods used in the various states of the United States. Basically all plans used are the same except that the allowable schedules are expressed differently. All schedules are represented either in barrels or proportionating factors, with well depth and acreage being the variable functions determining the quantity of the allowable for a particular well. The depth factor in such schedules is considered to provide a reasonable ratio proportionate to a well's drilling, completion and operating costs, while the acreage factor could be considered a ratio proportionate to the reserves of a well. Consequently, the allowable for a well will increase as some function of an increase in well depth and acreage assigned to it. It should be noted that such schemes for proration permit the recovery of drilling and completion costs from production and encourage larger spacing units through the use of the acreage factor.

The market demand determined through nomination hearings similar to those held in Alberta is distributed by totalling the well allowables within the marketing area, calculating an appropriate proportionating factor, and then adjusting the well allowables by this factor to arrive at a current well allowable. Several of the states practicing proration in the full sense (Texas, Oklahoma, Kansas and New Mexico) exempt ${ }^{30}$ certain production from market demand proration; i.e., marginal wells,

25 The "residual market demand" was simply the difference between the market demand and the sum of the economic allowances for the Province.

20 Supra, n. 2, at 10 defines: "MPR or maximum permissible rate" as the Board's estimate of the MER of the average well in a pool, and "Pool MPR" as the Board's estimate of the pool MER.

27 Texaco Canada Ltd., Submission to the Oil and Gas Conservation Board on Proration of Oil Production to Market Demand, Fisure 1 (July 31. 1963).

28 Supra, n. 2, at 176

20 Ballou and Dutton, Comparison of Oil Proration Methods in the Various States (June 1963), 15 Journal of Petroleum Technology 595. Also see Interstate Oil Compact Commission, $A$ study of Conservation of Oil and Gas in the United States, 1964 89-114. 30 Ballou and Dutton, id, at 596-97. 
secondary recovery schemes, discovery bonus. The production from these sources generally accounts for $10-20 \%$ of the market demand, although in Texas it may be as high as $50 \%$ of the market demand. Also Texas theoretically uses a system whereby the MER of production is determined for each pool in the state, usually on the basis of the rate to be applied to the top allowable wells in the field. However, except for the older major reserve fields, the MER's have a remarkable propensity to equal the well allowable rates dependent upon depth and acreage. $^{31}$

\section{Alberta Scheme}

The Alberta 1950 proration scheme, due to the economic allowance concept, was much the same as the schemes in use in the United States. However, it, as the Texas scheme, purported to give additional benefit to the wells completed in the prolific pools by prorating the residual market demand on the basis of pool MPR's. The aggregate of the economic allowances in the Province usurped a major portion of the market demand even under the post 1957 period when the initial and operating allowance concept was implemented. Effectively, this reduced the residual demand to a very small portion of the total market demand so that by 1960 virtually no credit was being given to the prolific pool.32 In essence therefore, Alberta's scheme provided for the distribution of the market demand on the basis of the individual well adjusted for its costs through the depth factor. Furthermore, there was no provision in the Alberta scheme to give credit to the acreage assigned to a productive well apart from the limited effect ${ }^{33}$ this factor had in the MPR formula. Consequently, a well of a certain depth would for all practical purposes be given the same basic economic allowance whether is was drilled on 40 acre or 320 acre spacing.

It should be noted that all of the U.S. schemes had endeavoured to consider acreage on a nearly proportional basis so that a well drilled on a larger spacing unit would obtain a correspondingly higher allowable. For example, in Texas, one barrel per day for each additional acre assigned to a well is granted over and above the basic allowable for a 10 acre spacing unit. Failure to account for acreage in the Alberta allowable schedule encouraged the over-drilling ${ }^{34}$ of many pools since the incentive was to develop pools on small spacing units in order to obtain the economic allowance. These defects possibly could have been remedied by placing greater emphasis on the acreage factor in the proration formula, or permitting the formation of production spacing units which would be granted an allowable that would vary proportionately with the size of the spacing unit.

In its 1964 Proration Plan, the Board completely departed from the well concept of allocating production. It now places emphasis entirely

31 Id., at 595-596.

32 Supra, n. 27

33 If MPR's had been the sole basis for prorating the market demand to pools, then the acreage assigned to a well would have been of much greater significance in determining the allowable for a pool, because the MPR for a well increases proportionately to the increase in acreage. However, because only the residual market demand was prorated on the basis of MPR's the acreage modifier in the MPR formula lost its significance in terms of the allowable that was granted an individual well.

34 "Over-drilling" or over-development is a form of economic waste: that is an unnecessary expense. With respect to the development of an oil pool, this term means that more wells than were necessary to effectively drain the pool were drilled within that more wells than were necessary to effectively drain the pool were drilled within
the pool. For a more comprehensive discussion of this problem see supra, $n$. 17, at 1158.. 
on the reserves in the pool as being the primary criterion for distributing the market demand among the pools. Distribution within the pool is simply a function of acreage and recovery factor and the well becomes irrelevant to the matter of proration among pools or within pools. However, because waste may result through the premature abandonment ${ }^{3 i}$ of wells in low reserve pools, the Board has incorporated a floor allowance into the plan which is designed to prevent this source of possible waste. Thus the Board has taken a different approach to proration techniques, placing into practice a completely new concept of prorationing to market demand.

\section{PRINCIPLES GOVERNING THE DETERMINATION AND ALLOCATION OF THE MARKET DEMAND}

Although the market demand is determined by the regulatory authorities through regular nomination hearings, the quantity at which it is fixed from month to month is essentially beyond the authorities' control as it is primarily a matter of supply and demand. Supply is a local matter determined by the magnitude of the natural resources of the province or state and the degree to which they have been developed. Demand on the other hand is basically an extraterritorial matter. For instance, in Alberta the major portion of our crude oil resource is exported to either eastern Canada or the United States. Hence, the demand will be governed not only by this country's economy as a whole but will be influenced by social and political considerations of the federal governments of both countries. The state or provincial regulatories, although able to govern the supply through their internal policies with respect to exploration and development, will have little influence upon the demand factor. Therefore, apart from being empowered to ascertain the demand figure for a particular period, there are no fundamental principles involved in so far as the state or provincial regulatory bodies are concerned. It should be noted that these authorities do exercise discretion in determining which grades ${ }^{311}$ of oil are subject to market demand. However, this again will be governed to a large extent by the supply and demand for the various grades of oil in the marketing area.

In apportioning the market demand, the regulatory authorities participate in a very important aspect of the proration scheme; that is they must first allocate the market demand to the pools, and then distribute these quantities among the wells in a pool. As indicated by the discussion comparing the various proration schemes in use, the quantity of oil that may be produced from an individual well will depend upon whether the pool or the well concept is adopted. Using the well concept, the market demand is primarily distributed among the wells irrespective of the pool in which the wells are completed. In this type of scheme the pool allotment step is for all practical purposes eliminated and proration becomes simply a matter of determining the market demand and distributing it among the wells in the province or state according to drilling, completion and producing costs. Such schemes must be con-

35 Abandonment at a time when a well is still physically capable of producing at economic rates.

30 For example, under the new plan the Board concluded that only light and medium crude oil would be prorated to market demand. Production from Turner Valley and other pools discovered prior to 1947 would continue to be regulated as at present, but outside the proration plan. 
sidered deficient because they do not give consideration to the characteristics of a pool in the allotment formula.

It is submitted that a sound approach to proration of the market demand is to first prorate it to the pools and then among the wells within the pool, subject of course, to certain paramount considerations. For example, although logically the allocation to the pools may be based pimarily upon the ratio of pool reserves to provincial reserves, there are superseding elements of waste, exploration and development incentive, public welfare, reasonableness of the result, etc., which may require some degree of departure from this simple allotment procedure. Under such a scheme of prorating the market demand, once the pool allotment is fixed, the distribution of this quantity among the wells becomes of secondary importance for by this time the allowable of the individual well within each pool will be generally defined.

In the same respect as the well concept fails to give some consideration to the pool and must be considered deficient, likewise, if the pool concept neglects to give adequate consideration to individual well costs, it may also be considered deficient. Even with to-day's advanced technology of geophysical and seismic data analysis, the well is still a fundamental part of the exploratory and development program. Hence, any scheme that ignores drilling and development costs in the proration formula is as greatly deficient as a scheme not providing for the characteristics of the pool.

For the reasons discussed, the provisions of the statutes empowering the regulatory authorities to allocate the market demand among the pools are couched in very broad terms enabling the regulatory authorities to consider all factors in the proration formula. Section 36 (1) (b) of the Oil and Gas Conservation Act of Alberta ${ }^{3 i}$ is a typical enabling provision which states that the Board shall allocate "the provincial allowable for crude oil, condensate and pentanes plus in a reasonable manner among the pools in the Province..." Since any allocation formula must be subject to waste prevention the provision will usually continue as follows "without waste to meet the provincial allowable so determined".

In distributing the pool allowable among the wells in the pool, consideration must first be given to the protection of correlative rights. ${ }^{34}$ Therefore, in exercising its authority in this area, the regulatory authorities must heed not only economic and engineering principles, but legal principles. By allocating an allowable to each well or unit area within a pool, the regulatory bodies are substituting a right which was enforceable under the common law as the "rule of capture" or as contractual rights under a lease agreement. Consequently, the third step in the proration procedure, although of secondary importance with

37 S.A. 1957, c. 63

38 Supra, $n$. 17, at 1153-1154 succinctly summarizes what is encompassed by the term "correlative rights" in the statement: "In the absence of regulation. owners of tracts within the limits of a pool have various rights and duties under general law ("common law" or non-statutory law). As already pointed out, each has the right to drill wells on his tract and produce as he pleases by non-negligent operations, even though oil or gas is drained from the lands of his neighbours, and each has the right, by drilling and operating offset wells to protect against drainage and to keep the oil and gas in his tract "at home", to use the language of the court in the BARNARD case. Each is also under a duty not to operate negligently to the injury of another owner, such as improperly shooting a well, or operating in a manner that reduces the ultimate recovery from the pool to the injury of all, such as dissipating reservolr energy. It follows that the owners are reciprocally interested in the pool, or they have reciprocal or mutual relations. They have correlative rights, also duties". 
regard to the quantity of oil that may be produced from a well, is of primary importance to ensure that each owner is entitled to recover his equitable share of the oil-in-place under his property. Recognizing this as the fundamental aspect of distributing the pool allowables, the legislatures have phrased the enabling provisions of such statutes similar to that adopted by Section 36 (1) (c) of the Alberta Act,"3b "by distributing the portion of the provincial allowable allocated to a pool in an equitable manner among the wells in a pool".

In 1942, a Special Study Committee and Legal Advisory Committee on Well Spacing and Allocation of Production of the American Petroleum Institute (hereinafter referred to as "the API Committee"), after undertaking a study of the proration schemes in use, published a report $^{40}$ which concluded that certain basic principles are applicable to allocation of a fixed market demand among and within the pools in the state. These principles would still appear valid today and are adopted as being sound principles applicable and adaptable, with minor variation, to any proration scheme in use today. With respect to allocation of the market demand among pools, the report listed the following principles:

(1) Stripper production should be exempted from restriction-such exemption to apply only to those pools which, if restricted, would yield less oil ultimately.

(2) Other fields should be restricted at least to rates which will permit the use of the most efficient producing practices.

(3) The state (provincial) allowable should be allocated among the pools on a reasonable basis so that undue discrimination will be prevented. Consideration should be given to reasonable market demand for the several grades of oil produced in the state.

(4) Subject to necessities of waste prevention, pools producing oils of similar grade should share in that part of the allowable applicable to such oilsallccation being made on a reasonable basis to avoid undue discrimination with consideration given to the relative developed oil reserves of each pool, and to the cost of development and operation of the pools, which cost is usually reflected by the depth of the wells.

The report listed the following as the principles that should govern distribution within a pool, namely:

(1) Physical waste should be prevented.

(2) Within reasonable limits, each operator should have an opportunity equal to that afforded other operators to recover the equivalent to the amount of recoverable cil underlying his property. The aim should be to prevent reasonably avoidable drainage across property lines that is not offset by counter drainage.

(3) Allocation of production within each pool should be such as to impose no undue hardship upen any operator. By way of explanation, the producing life of a property which is affected by structural position depends partly upon regional migration, this life can be relatively long or short, and the ultimate recovery high or low, by the method of allocation. Clearly, then, regional migration must be taken into account in order to permit the properties which are being drained as a result of unavoidable regional migration to recover oil at a faster rate than the properties which ultimately benefit from such migration. What should be done in any particular field to prevent undue hardship depends upon the conditions in the field.

(4) The method of allocation should be simple enough so that its administration will not break down because of its complexity.

(5) Under certain circumstances, some of these principles may be incompatible with others. In such cases compromise or adjustment must be made.

It is apparent from a statement of these principles that the prevention of waste is the supervening element. Thus to complete the implications of the principles, one must understand what is considered

3o Supra, n. 37.

10 API, Standards of Allocation of Oit Production (1942). 
waste. In its conclusions the API Committee felt that waste results from the following causes:

(1) production in excess of the market demand;

(2) production of individual wells at excessive rates, damaging either the well or reservoir;

(3) development on improper well spacing patterns or improper well density;

(4) improper well completion;

(5) improper production of multiple zones;

(6) excess production of water and/or gas;

(7) failure to supply suitable methods of pressure maintenance and secondary recovery where economically justified.

Some may consider these principles outdated in view of the profound advances made in petroleum technology over the last two decades. However, advances in the field of proration have not been as dramatic, as most regulatory authorities, with the possible exception of Alberta, are using concepts adopted in 1930-concepts which may still be summarized in a sentence. Allocation of production among pools, and within a pool, must be on the basis of sound principles of engineering, economics and law.

\section{E. ANALYSIS OF THE BOARD'S PRORATION SCHEME WITH REFERENCE TO FUNDAMENTAL PRINCIPLES OF PRORATION}

\section{General}

Initially the Board must be commended for taking what is probably the most progressive step towards the logical prorationing of oil of any regulatory authority in North America. It is the only authority which utilizes the three step method for allocating the market demand, by first determining its quantity, then allocating it to the various pools in the province, and finally distributing this quantity among the individual wells in the pool. In its report, the Board considered virtually all the fundamental principles inherent in a comprehensive proration scheme and its conclusions were similar to those made in 1942 by the A.P.I. Committee. ${ }^{11}$ However, the Board did not indicate it was cognizant of this study. In fact, it becomes apparent upon reading the Board's report that it was based entirely upon submissions made to it by interested parties. Considering that some of these were extremely biased and gave little regard to principle but were based primarily upon economics, the Board's resolution of the problems related to proration was remarkably similar to that of the A.P.I. Committee.

There is little doubt that the petroleum industry has played a major role in the development of Alberta's industrial potential not only through the development of petroleum and natural gas resources in the Province but through secondary effects such as the construction of numerous roads into virgin territory, providing secondary sources of revenue to the landholders through lease rentals and royalties, enriching government coffers through bonus and royalty payments, requiring a host of secondary industries to provide the services for the development companies and finally making available cheap sources of power and energy for the individual citizen and for industry. Yet, there were no public representations at the Board hearings from either the government or other public bodies having inherent interests expressing their position with respect to proration. Certainly, the operating companies 
would individually stand to gain or lose more than anyone else from a change to the proration scheme; however, this is no reason why their submissions should have been the only representations heard. It is submitted that representations from all bodies affected would have assisted the Board to consider proration in a broader perspective.

Acknowledging that some revisions were necessary to the 1950 proration scheme, was it necessary to completely change the concept of proration in Alberta to remedy its defects and accomplish new objectives? The general consensus in Industry is that, since long term financing is an integral part of any oil exploration and development program, abrupt changes to proration should not be implemented unless absolutely necessary. The Board recognized the following deficiencies under the old plan;

(1) encouragement of the drilling of unnecessary development wells;

(2) insufficient incentive for maximum recovery by enhanced recovery schemes; 42

(3) insufficient incentive to explore for new oil reserves;

(4) administrative complexity;

(5) increased operating costs.

Examining these in greater particular, the Board concluded that there was no issue with respect to point (3), as the real incentive for exploration arose from operators' expectations of making a discovery, although the proration plan may influence the type of exploration and the number of operators participating in it."3 Administrative complexity was a problem related particularly to the application of the terminal transfer factor ${ }^{4}$ to enhanced recovery schemes and unit operations which resulted in the necessity for arbitrary rules which became difficult to administer. ${ }^{4 ;}$ Finally the matter of increased operating costs was part and parcel of point (1), but going a little further in that the old proration scheme not only encouraged the drilling of unnecessary wells, but the production of unnecessary wells. In essence, therefore, there were only two basic deficiencies in the old plan, both resulting in "waste", namely:

(1) It encouraged the drilling and production of unnecessary wells;

(2) It provided insufficient incentive for maximum recovery by enhanced recovery schemes.

If these were the only deficiencies of the old scheme, then it is submitted that it was unnecessary to so completely change the concept of proration in Alberta. Certainly the encouragement of over-development ${ }^{46}$ seemed to be the main deficiency of the scheme, and as previously stated, this was due to the absence of an acreage factor in the economic well allowance formula and not as the Board states in its report: "The Board believes this excessive productivity has resulted largely from the high minimum well allowances and the effect of the life factor in determining MPR's." There is little doubt that the acreage factor was introduced into proration schemes in the U.S. to curtail economic waste caused by over-development.

Under Alberta's 1950 proration scheme, there was little or no incen-

42 A scheme of production whereby recovery is improved and commonly includes flooding, pressuring and cycling of the reservoir, or a combination of these.

43 Supra, n. 2, at 51-52.

4 OIl and Gas Conservation Board. Letter to all operators Re: Economic Allowance Allocation Unit and Project Areas and all Fluid Injection Schemes, Sept. 12, 1961. 45 Supra, n. 2, at 52-53.

10 Supra, n. 34 .

47 Supra, n. 2, at 50. 
tive (apart from greater ultimate recovery) to initiate secondary recovery and pressure maintenance schemes. However, it is again submitted that it was not necessary to resort to a reserves system of prorationing in order to provide sufficient incentive. Some proration schemes in the United States exempt enhanced recovery schemes from proration, and this could have been considered in Alberta.

It is not suggested that the above would have been the best solution to the deficiencies of the old scheme, but it should illustrate that the Board went further than was necessary to remedy the deficiencies of its old plan. An examination of the Board's objectives for prorationing does not help one to understand the changes made by the Board. The Board was of the opinion that the basic objective of proration was the satisfaction of the statutory provisions, in particular, Sections 4 and 36 of the Oil and Gas Conservation Act. ${ }^{48}$ In addition, the following were considered objectives either implicit in the statute or desirable from an economic standpoint:

(1) to encourage efforts to enhance the recovery from pools;

(2) to discourage the abandonment of wells before the production of all apparently economically recoverable oil;

(3) to assure production from low reserve per acre discoveries which appear economically recoverable;

(4) to provide a system which is relatively easy to administer;

(5) to provide a method of allecation which is operable over a wide range of market conditions, both as to supply and demand and allow continuity in the production from and development of pools;

(6) to encourage exploration and not deter any party interested from exploring for reserves;

(7) to maintain the participation in the industry by anyone interested;

(8) to encourage the economic optimum development within pools, and minimize the cost of oil.

Except for objectives (1) and (8) above, which are simply a different way of stating the two deficiencies noted previously, it is doubtful that the new scheme satisfies these objectives any more than did the old scheme. The Board has therefore, not established that a fundamental change was necessary to remedy the defects of the old plan. Be that as it may, the Board's new scheme is undoubtedly an improvement over its former plan and the change over has been tempered by providing for a four year transition period. Nevertheless, the Board, being a public body has the onus of establishing the need for major changes to its proration policy, and in this case does not appear to have unequivocally established that a major change to the old plan was necessary to remedy its defects and accomplish desired objectives.

\section{Allocation Among Pools}

(a) Statutory Requirements

By virtue of Section 36 (1) (b) of the Oil and Gas Conservation Act, ${ }^{49}$ the Board is empowered to allocate the market demand among the pools in the Province "in a reasonable manner" and so that the allowable thereby determined may be produced "without waste". It is apparent that these provisions provide a wide degree of latitude, since both industry and the Board seem to feel that the Board's old plan for proration, and the current plan are within these provisions. The Board expressly stated that an amendment to the Act was unnecessary in order to adopt the new scheme. If this is the case, the provision is virtually 
meaningless as the schemes employ entirely different concepts, and what is considered reasonable under one is no longer reasonable under the other. For instance, the Board under the old scheme believed it reasonable that the economic allowance should enable the operator to recover drilling and operating costs. ${ }^{50}$ Under the new scheme it has substituted the floor allowance for what previously was referred to as the operating economic allowance and reduced it by about one-half. Its prime purpose now is to prevent the premature abandonment of wells. ${ }^{51}$ Such a fundamental change in philosophy will undoubtedly have a great influence on the quantum of the market demand which each well is allocated. It is possible that either philosophy is reasonable as an integral part of the particular concept employing it, yet it would be a futile exercise in semantics to endeavour to establish either scheme as being intra or ultra vires of the provisions of the Act. Accepting the position that the Board's new plan is within the provisions of the Act, this paper will take an objective approach to the Board's new plan by testing it on the basis of fundamental principles of prorationing.

\section{(b) Characteristics of Pool as a Factor}

Allocation of the market demand for oil among the pools in the Province is the second logical step for prorationing production after determining the market demand, but not a single submission to the Board expressly recognized it as such. Virtually all the submissions recognized that reserves of a pool were a factor that should be considered somewhere in the proration plan, but none placed it in its proper perspective as being simply a factor which could be used to give credit to the characteristics of a pool when prorating production to the pool. Many of the submissions confused this with economics, over-development, exploration incentive, etc. Granted, these factors may be affected by proration to pools but they should not be the primary consideration for prorating to pools initially. Nevertheless, the Board has clearly adopted allocation among pools as the second step in its prorationing plan. This is evident from the format of its report as well as being implicit in the definition of a floor allowance-_"the minimum allowance of a well is a system whereby all the Provincial allowable is allocated and distributed according to proration factors subject to adjustment so that every qualified well may receive its minimum allowance".s2

Once it is accepted that allocation of the market demand to pools is the appropriate second step of proration, the question then arises in accordance with what principles and parameters. The principles have been previously set out in this paper and it may be noted that proration to pools on the basis of reserves has long been advocated. However, it is also noteworthy that it is not the sole parameter that could be used. Other factors which are generally considered representative of the characteristics of a pool are the MPR for a pool, the mobility ratio:" and the life index of a pool. The Board considered all of these factors and chose only to give weight to the reserves in a pool in allocating the market demand among pools. With respect to the other parameters,

so Supra, n. 23.

51 Supra, n. 2, at 66.

52 Supra, n. 2, at 9.

53 Imperial Oil Ltd. Submission to Oil and Gas Conservation Board on the Allocation of the Provincial Allowable for Crude Oils, 11 (July, 1963). 
the Board concluded that the MPR and mobility ratio modifiers would promote the development of unneeded productivity through overdevelopment which would be contrary to the objective of optimum development.it Furthermore, the Board felt the incorporation of the life factor would adversely affect the development of low permeability pools, especially those with low reserves per acre.

The Board's decision to consider only reserves in allocating the market demand will, together with provisions for the formation of production spacing units, encourage optimum development within a pool so that little or no incentive remains to develop excess productivity. However, some excess productivity is required not only to meet peak seasonal demand requirements, but those resulting during periods of emergency. The need for excess productivity was amply exemplified during the Second World War when both the United States and Canada had difficulty meeting the high crude oil demand requirements. Although this is not an immediate problem in Alberta since ample productivity was developed under the old proration plan, it is a matter which should be considered a potential weakness of the new plan.

Due to the fact that holdings of the petroleum and natural gas rights of the Province are diversified, some excessive productivity will be developed since it will not always be possible to develop just enough productivity to meet the allowable. Also, if it is economically attractive a prudent operator will take measures to ensure that the allowable will be producible. Nevertheless, it is doubtful that these are adequate safeguards to provide for the right amount of excess productivity. Incorporation of productivity modifiers such as MPR and mobility ratio into the proration plan would encourage the development of excess productivity, but as the Board concludes the overall effect may not be desirable. Possibly the answer lies in requiring the development of excess productivity in pools capable of additional potential and where the costs would be minimal.

\section{(c) Recovery of Drilling and Completion Costs}

The API committee concluded that consideration must be given to the relative developed oil reserves of each pool and the cost of development and operation of the pools when allocating the market demand among the pools. As previously discussed, the Board's new plan has endorsed the use of reserves as a basis for allocating the market demand among pools; however, by failing to provide for the recovery of drilling costs, it has chosen to disregard the "cost of development" as worthy of consideration. Failure to ensure the recovery of drilling costs from pools capable of doing so, is a major departure from its old plan as well as from current schemes in use in the United States. Under these plans the economic allowance or depth bracket allowable reflects the development costs of a pool. The Board's concept of a floor allowance however presents a new philosophy with respect to the purpose of a basic allowable. ${ }^{\mathrm{s}}$

It is surprising that the Board has abandoned the concept of the economic allowance after utilizing it for prorationing the major portion of the market demand in the last 14 years. This concept is still being 
used to prorate oil to market demand in all of the states of the United States utilizing proration. It may be true that under the old scheme, the prolific pool was receiving little credit due to the economic allowance usurping a large portion of the market demand; however, this in itself is not a valid reason for entirely ignoring drilling costs as provision for their recovery is based on sound principles of economics. When proration was instituted in the various states of the United States and in Alberta the reasoning was that the investment in a well was necessary not only to discover but to develop these resources, and as such, should be recoverable from production. Is the role of the well as part of the exploration for and the development of petroleum resources any different today than it was a decade ago? It is submitted that it is not. The petroleum industry may have advanced in technology with respect to exploration for and production of petroleum, yet the well is as fundamental today to the exploratory and development process as it was at any time in the past, and the costs are proportionately as great. For these reasons, failure to account for the recovery of drilling costs in a proration formula is contrary to sound principles of business economics.

Furthermore, failure to account for drilling costs in the formula allocating the market demand to the pools may result in physical and economic waste. ${ }^{\text {:t }}$ Allocation solely on the basis of reserves will enable the recovery of drilling costs for the average or better reserve pool, and the floor allowance will prevent the premature abandonment of wells completed in a pool; however, neither of these factors takes into consideration the development of low reserve pools in the Province. In essence, therefore, if a pool has insufficient reserves to receive an allowable on the basis of reserves to pay-out drilling costs, the pool's resources will not be developed. It would be uneconomic to do so, as the floor allowance only provides for return on completion and operating costs. According to the Board's own statistics"i about 12 percent of the Province's reserves may be expected to be left unexploited if past discovery ratios are taken as indicative of future discoveries. This would seem to be an unnecessary waste of the Province's resources and contrary to the fundamental principles of conservation.

In dealing with this matteris the Board stated that the major portion of the marginal reserves could be economically developed on wide spacing. This may be true in some instances but development on spacing units larger than one-quarter section may not be practical for two reasons:

(1) many of the Petroleum and Natural Gas (P \& NG) Leases in the Province are only one-quarter section in area.

(2) the size of the spacing unit required to provide an economic allowable may exceed the effective drainage area.

Considering the first point, it is essential to recognize that the minimum area for leasing $\mathrm{P} \&$ NG rights and for drilling on such leases is one-quarter section. These minimum areas may have been established for different reasons, however, the fact remains that this is their extent at the present. It is conceivable that certain quarter section parcels may not be economic to develop because the operator will not be in a position to drill and complete on wider spacing. Yet immediately adjacent to

5i Supra, n. 8.

5i Supra, n. 2, at 28.

s8 Supra, n. 2, at 76-77. 
such a parcel, another operator may have larger holdings and therefore be in a position to economically develop the same by drilling and completing on wide spacing. Such arbitrary development would not provide equal protection to the correlative rights of holders of $\mathrm{P} \& \mathrm{NG}$ Leases, which said protection is one of the principle functions of a conservation authority prorating production to market demand.

With respect to the second point, it has generally been accepted in the Petroleum Industry in Alberta that one-quarter section spacing is sufficient to effectively drain most oil reservoirs, and therefore, the maximum spacing unit for purposes of drilling and producing is onequarter section. Recognizing that this may not be the most efficient production area, the Board has adopted a policy permitting the formation of production spacing units as large as two and one-half sections. All of this is well and good; however, if the size of the production spacing unit is governed by the area that is required to provide an economic allowable, the purpose of the production spacing unit has been misconstrued. In the same respect as the economic allowance should not govern development of a pool, the quantum of allowable required to permit economic development of a pool, should not govern the size of the production spacing unit.

In summary, the Board's suggestion that marginal reserves may be developed by drilling and completing on wide spacing will not protect the correlative rights of holders of all P \& NG Leases, nor is it a proper application of the production spacing unit concept. Ensuring the recovery of drilling costs from a well's production would provide everyone with an equal opportunity to develop their property and would also make it unnecessary for holders of P \& NG Leases to form spacing units which may be too large for proper depletion of the reserves.

Providing for the recovery of drilling costs in the form of an economic allowance, may slightly increase the cost of oil in the Province, but, as the Board said of the floor allowance, such increased costs "should be considered secondary to conservation" and the prevention of waste. ${ }^{.9}$ One of the submissions to the Board placed the Board's function in this regard in the proper perspective: ${ }^{60}$

We suggest a basic axiom to be followed in the conservation of the Province's oil reserves is that all oil reserves physically capable of producing oil at a profit should be granted an adequate basic allowance to do so; and that any departure from regulatory policy from this axiom would be anti-conservation in effect to what might, in one sense of the word, be termed "highgrading" of the Province's natural resources.

No one can say now whether the future oil potential of this province consists of several major oil fields or an aggregation of many smaller and low reserve oil fields, but the latter possibility is one for which our present regulations must provide.

Unless these factors are taken into account, it cannot be said that allocation among pools is without undue discrimination which seems implicit in the phrase "in a reasonable manner"."1

In 1962 a modified method for leasing Crown lands was adopted in the southeastern part of the Province" (Block " $A$ ") to encourage the

50 Supra, n. 2, at 28.

no Supertest Petroleum Corporation Ltd. Response to Submissions to the Oil and Gas Conservation Board concerning the Proration of Oil Production to Market Demand 4 (Sept. 27, 1963).

(i1 Supra, n. 15 , s. 36 (1) (b).

62 The Mines and Minerals Act, S.A. 1962, c. 49, Pt. V. 
development of the remaining reserves. The prime reason for adopting the modified system was to provide for the more rapid turnover of land so that remaining oil and gas resources in this area, generally of the low reserve nature, would be developed. By failing to ensure the recovery of drilling costs from the production of low reserve pools the Board has in effect negatived the additional incentive produced by the change in leasing regulations in this part of the Province. It is presumed that these provisions would be extended to the remainder of the Province once development of oil and gas resources reaches the same stage it had in the Block " $A$ " area. However, since the Board's proration plan has rendered the development of low reserve pools uneconomic, any such extensions would have little effect, as there will be no incentive for industry to develop these. The Board's plan for proration therefore does not appear entirely consistent with other Provincial objectives for development of marginal and low reserve pools.

\section{(d) Prevention of Waste}

In allocating production to a pool, the method adopted must always be subject to the necessity of waste prevention. In addition to the waste resulting through providing inadequate incentive to develop the low reserve oil pools in the Province, other forms of waste which are specifically referable to the pool rather than the well include:

(1) premature abandonment of wells in a pool;

(2) over-development of a pool;

(3) failure to institute secondary recovery and pressure maintenance schemes where economically feasible in a pool.

The first, due to the economic allowance concept, was not a problem under the Board's old proration scheme, and by adopting a reserves basis of allocating the market demand to the pools the Board has created a new problem. Being fully cognizant of this fact the Board appears to have used a sound approach to resolving it by adopting the floor allowance. On the other hand waste through over-development and insufficient incentive to institute enhanced recovery schemes were the prime defects causing physical waste under the old scheme. It is questionable whether the Board had to change from a well concept to a reserves concept to remedy these matters; however, the use of the latter has undoubtedly improved the incentive for the implementation of enhanced recovery schemes. Since the purpose of enhanced schemes is to increase recovery and hence reserves, a reserves method for allocating the market demand can only encourage the institution of such projects. With respect to over-development, the adoption of flexible production spacing units together with the validation rules will discourage overdevelopment which was inherent in the Board's old plan.

Apart from discouraging the development of low reserve pools, the Board's plan for proration appears to have made adequate provision for preventing waste. Nevertheless, this is a major deficiency of the present plan and measures should be taken to correct it. If the Board was previously concerned with the waste caused by over-development and inadequate incentive for enhanced recovery schemes, it should be equally concerned that the present plan will create waste through insufficient incentive to develop the low reserve oil pools in the Province. This matter may be aggravated by the recent discoveries in the northern 
part of the Province of prolific oil pools, which, on the basis of the reserves concept of allocation, will tend to usurp a large share of the market demand.

(e) Ultimate versus Remaining Recoverable Reserves as an Allocation Base

With respect to the matter of whether ultimate ${ }^{63}$ or remaining reserves ${ }^{34}$ should be used as a basis for allocating the market demand to the pools, the submissions to the Board were divided; however, generally those submissions that advocated a low basic allowance also advocated the use of ultimate reserves. It would be superfluous to delve into the respective advantages and disadvantages of using either of these as a proration base as these were discussed by all submissions which considered allocation to pools on the basis of reserves as a feasible concept. The Board being cognizant of these, refused to take a position itself on either one or the other and compromised by allocating the market demand to pools $50 \%$ on the basis of ultimate recoverable reserves and $50 \%$ on the basis of remaining recoverable reserves. This approach may tend to appease both factions but the use of ultimate reserves as a basis, whether on a partial or whole concept, is over-emphasizing the reserves of a pool at any time after initial production takes place from the pool. This effect becomes even more exaggerated as production continues, and eventually a time will be reached when the pool is not capable of producing its allowable and production will have to be restricted in accordance with good engineering practice or a calculated production rate similar to either the MPR or the more recently adopted Maximum Rate Limitation ${ }^{65}$ (MRL). In either case there will be the incentive to produce such pools at capacity so that the possibility of reservoir damage and hence waste will continuously be prevalent. Not only will it be necessary for the Board to examine the state of depletion of each pool periodically to ensure that reservoir damage is not resulting, but close surveillance of field operations will also be necessary. Therefore, in addition to providing an unrealistic figure for prorating to a pool after initial production takes place, the ultimate reserves concept will be conducive to creating waste through reservoir damage and will be extremely difficult to administer and enforce during the latter stages of production of prolific pools.

The use of remaining recoverable reserves as a basis has none of these inherent ramifications; its prime disadvantage being that it may in the latter stages of depletion of pools encourage premature abandonment of wells due to low allowables. The floor allowance under the new plan simply resolves this possibility of waste and is a logical second reason for adopting a floor allowance system. The Board expressly denied that this was a consideration for adopting a floor allowance. ${ }^{\circ 0}$ It is submitted there is no logical reason why this could not be the second reason for adopting a floor allowance. There is no difference between a well initially being placed on a floor allowance due to lack

63 Supra, n. 2, at 10, defines "ultimate reserves" as the remaining reserves of a pool plus the volume of oil that has been produced from the pool.

64 Id., defines "remaining reserves" as the total reserves, recoverable by methods employed in the pool, remaining in the pool from time to time.

65 Oil and Gas Conservation Board, Report and Decision on Review of Plan for Maximum Oil Production Rate Limitation in Alberta, OGCB 65-3.

66 Supra, n. 2, at 109. 
of reserves under the present concept, and one placed on a floor allowance at some point later in its productive life. In fact, the latter has had the greater opportunity to recover development and production costs and the application of a floor allowance is less onerous economically.

\section{Distribution Within Pools}

The Oil and Gas Conservation Act, Section 36 (1) (c) ${ }^{67}$ provides that the production allocated to a pool shall be distributed in "an equitable manner" so that each well owner has the opportunity of producing or receiving his just and equitable share of the oil in a pool. Just as the provision for allocating the market demand, gives the Board wide powers of distributing the allowable, this provision is equally broad in its empowering scope; the only criterion being that the Board justify the manner adopted as being equitable and without waste. As previously noted the Board in this area is also dealing with rights which in the absence of the statute would be governed by common law. Consequently, it is only reasonable that the Board should be cognizant of any fundamental legal principles adopted by the courts when formulating policy with respect to the equitable distribution of production within a pool.

There are many factors which could be considered in distributing production among wells in the pool; however, the courts and regulatory bodies in both Alberta and the United States have chosen to employ relatively simple methods which for all practical purposes have a result as equitable as any complicated method incorporating all factors. The two most commonly used methods are the area method, which distributes the pool allowable among the wells according to the ratio of the area assigned to a well to the area of the pool; and the reserves method, which distributes the pool production in the ratio that the reserves attributable to a well are to the reserves of the pool. Both of these methods were considered by the Board in its recent plan for proration. The Board adopted the area method modified by a recovery factor as being the most appropriate method for distributing the pool allocation. ${ }^{68}$

With reference to the basic principles for distributing the pool allocation among wells stated earlier in this paper, it may be noted that strong emphasis was placed upon lease line drainage and regional migration of oil causing inequities during the production of a pool. Neither the reserves nor the area method of distribution take into account either of these, although as the Board concludes when comparing the two methods, the area method seems "to provide a fairer opportunity for shorter lived wells to recover reserves that could be attributed to them. It also permits wells having advantageous structural positions to reap some benefit from this position"." This is a very important factor in the equitable distribution of a pool's allocation among the wells and should have been thoroughly investigated. The computer in today's technology may facilitate the incorporation of such a factor into a distribution formula with relative ease. The alternative, of course, is to require unitized operations where the need for such a factor disappears.

With respect to waste prevention as it pertains to the individual

Gi Supra, n. 37.

G8 Supra, n. 2, at 176

69 Supra, n. 2, at 126 . 
well, i.e. improper completion, excessive production of water and gas, etc., there has been no fundamental change to policies developed over the years, which have proven themselves sound and workable. It is submitted the Board exercised good judgment in retaining these.

\section{F. ECONOMIC EFFECTS OF NEW PRORATION PLAN}

Although a proration plan must be concerned primarily with conservation, prevention of waste and the protection of correlative rights, there are economic considerations which may make it undesirable to implement a scheme based entirely upon these principles. Many of the submissions made to the Board considered these as the prime factors and virtually ignored the basic necessity and reason for a proration scheme in the first place. For example, one submission ${ }^{70}$ was based entirely upon the premise that a proration scheme must be designed to enable the development of the lowest cost oil so that we may remain competitive in the marketing of it. On the other hand, another submission ${ }^{i 1}$ stressed the importance of participation by all interested as a key factor in drafting a prorationing policy. These factors undoubtedly have a bearing on a proration plan, but as the Board recognized, to be placed in proper perspective, they must be considered secondary to the prime principles of conservation and waste prevention.

The submissions, of course, were fostering ideas which were of the greatest importance and concern to the parties making them. It was each party's prerogrative to emphasize whatever factors and principles it considered relevant and important. However, at this time, the Board's plan can be considered in retrospect so that it is possible to make an objective appraisal of the effect the plan will have on the various economic entities related to it, and whether in the final analysis the plan is in the best interests of the Province and industry.

\section{Provincial Oil Royalty and Bonus Revenue}

Although mentioned in some submissions, the Board did not publically consider the effect a change to the Province's proration scheme may have on the revenue derived from oil royalities and bonuses paid at Crown Sales of Petroleum and Natural Gas Rights. Since this is one of the major revenue sources of the Province, it would have seemed worthy of consideration.

Generally, due to a sliding royalty scale, ${ }^{72}$ and the fact that fewer wells would be producing a greater portion of the market demand under the new plan, royalties may be expected to increase. However, a compensatory effect will result by the production of a greater number of wells located in the less prolific pools being placed on a lower allowable and hence a lower royalty rate. It is difficult to estimate the net effect without a detailed analysis of the matter, but it would appear that the overall royalty revenue should increase under the new plan.

With regard to bonuses, these should greatly increase for the high reserve prospects, and decrease for the lower reserve prospects. Again there should be a compensatory effect, but whether or not the difference

To Supra, n. 53.

i1 The Independent Petroleum Association. Submission to the Oil and Gas Conservation Board concerning the Prorating of Oil Production to Market Demand (July 30, 1963 ).

;2 Crown Royalty payable based on a well's monthly production:

0- 750 bbls. at $8 \%$

$750-2700$ bbls. at $20 \%$
Over-2700 bbls. at $162 / 3 \%$ 
will be substantial will depend entirely upon the nature of the undeveloped oil resources of the Province. In any case, it is submitted that these matters should have been dealt with by the Board in its report on the new proration plan.

\section{Participation by Operators-Related Servicing Industries-Public Benefit}

Since these matters are interrelated the effect that a change to the proration scheme would have upon these will be discussed under one head. These matters were, at least in part, dealt with by the submission made to the Board by IPAC. ${ }^{\text {is }}$ In effect, IPAC stated that any change which would further reduce the economic allowance would make it economically impossible for many of the independent companies operating in the Province to continue to do so, particularly with respect to the exploration for and development of new reserves in the Province.

Participation by fewer operators may be anticipated due to the distribution of the recoverable reserves per well within the Province. Although the smaller independent companies operating in the Province have conducted from 55-65\% $\%^{74}$ of the drilling activity in the Province in exploring for and developing the Province's reserves, the recoverable reserves ratio per well is considerably lower than that of wells drilled by the larger or major companies participating in the Province. The main reason for this is that the smaller companies, due to limited financing capabilities, are limited to the development of less lucrative acreage in a discovery area. Much of such acreage has been developed on the premise that the well would be obtaining an initial and subsequently an operating allowance which even though the reserves may be small, would permit pay-out of drilling, completion and operating costs, and provide a reasonable return on investment. Hence, IPAC reasoned, that these operators will, through a simple matter of economics, be precluded from participating in further development of marginal reserves if greater emphasis is placed upon recoverable reserves in the proration plan.

Not only will this tend to create waste through lack of incentive to develop the low reserve areas, but the reduction in participation can only serve to adversely effect the Province's economy. Furthermore, it will tend to create a monopoly of the oil resources in the Province in the hands of a relatively few major companies. None of these factors can be considered advantageous to the general social and economic interests of the Province. Of paramount importance, however, is the fact that it will tend to create waste.

Neither the submissions to the Board, nor the Board itself, considered the effect a change to the proration plan may have upon secondary industries in the Province dependent upon the operators for their livelihood. A reduction in participation by operators will surely result in a reduction in revenue to these services. For every well that is not drilled there will be one less drilling rig employed, one less casing string used, one less cementing operation, one less mud program, one less completion operation as well as a reduction in the surface production facilities required. All of these are essential to the livelihood of numerous second-

73 Supra, n. 71.

74 Dome Petroleums Ltd. Response to submissions presented on Prorating to market demand (Sept. 27, 1963). 
ary services in the Province, which in turn disperse a large portion of their income in the form of salaries, acquisition of equipment and raw materials, etc., within the Province. Therefore, by reducing participation by operators, there is an adverse economic effect upon a large segment of the population.

It could conceivably be economically advantageous to the Province to have as much money as possible spent on the development of the Province's oil and gas resources, since it is from this source that the individual stands to benefit most directly. In other words, inefficiency could be considered efficacy from this point of view. Be that as it may, it would be irrational to endeavour to justify over-development of a pool's reserves on the basis that this is of the ultimate benefit to the individual citizen in the Province. Economic development is still a fundamental concept of a free enterprise system and it should not be defeated needlessly. However, it is equally irrational to permit the waste of resources in the Province when it is within our means to prevent it by permitting full participation by persons interested. By providing for the recovery of drilling costs in the proration formula, the Board would, at least partially, eliminate the adverse effects created by emphasizing entirely the recoverable reserves of a pool.

\section{Exploration Incentive}

Many of the submissions to the Board considered this a prime factor in deciding upon a proration scheme, but there was a complete divergence of opinion on what the proper incentive should be. Some operators ${ }^{75}$ suggested that the plan should encourage the development of the high reserve fields; thereby reducing the unit cost of oil per barrel and placing this Province in a better competitive position with respect to markets. On the other hand, IPAC ${ }^{i 6}$ believed that a proration plan must encourage participation by a maxium number of operators so that all resources in the Province, prolific or otherwise, may be discovered and developed. Being unable to reconcile these views, the Board came to the conclusion that the "real incentive for exploration is the expectation of making a discovery." "i

There can be little doubt that by emphasizing the reserves in the proration formula, the exploratory effort with respect to the high reserve pool will tend to be encouraged. In itself this could be considered a desirable feature of a proration plan, provided that the plan also retains the incentive to explore for the lower reserve pool. In the end, the plan should foster the development of the maximum amount of the oil resources of the Province at the optimum unit cost. Only when a plan meets these qualifications can it be said to provide the proper exploratory incentive.

The Board clearly endorsed the suggestion that the plan must encourage the development of high reserve pools since it adopted reserves as the sole basis for allocating the market demand to the pools in the Province. By definition the floor allowance cannot provide any incentive for exploration as it is designed only to preclude premature abandonment of wells. Reserves are, therefore, the sole criterion which

\footnotetext{
is Supra, n. 70.

70 Supra, n. 71.

77 Supra, n. 2, at 52.
} 
will govern exploratory effort, providing incentive only to discover the prolific pool. The development of the low reserve pools has been. rendered uneconomic under such a scheme because it leaves no incentive to explore for such pools, and the ultimate result could be considered a waste of the oil resources of the Province. Again, it is submitted that if the Board had allowed for the recovery of drilling costs from a well's production, this would have helped to provide a broader incentive for the exploitation of the Province's oil resources.

\section{G. EFFECT OF PROLIFIC DISCOVERIES ON NEW PLAN}

One of the express objectives of the Board was to design an allocation formula which would accommodate wide fluctuations in demand, productive capacity, price and costs, without change and thereby enable operators to plan exploration and development programs accordingly. Little did the Board realize that even before its plan was fully implemented, it would have to cope with a completely different distribution of the Province's reserves. Somewhat more than six months after the Board published its report, oil was discovered ${ }^{i s}$ in the Muskeg and Keg River formations in the northern reaches of Alberta, a formation which had heretofore been found water laden, but which had tremendous potential as a petroleum reservoir if found to contain oil. Conservative estimates today place the potential reserves of the formations in this area at the equivalent of reserves discovered prior to that time. Current proven reserves from this source have been estimated at about 1.5 billion barrels, ${ }^{71}$ which is an increase in Provincial reserves of about 25\% since the Board's plan was initiated. It is inevitable that such a large increase in reserves will affect the distribution of production from well to well if the system of prorationing is based almost entirely on the reserves of a pool. Although the Board endeavoured to design a versatile scheme adapatable to changing conditions, it is contended that the plan was designed primarily to cope with general increases in productivity and marketability, since the Board used past statistical information and data ${ }^{\mathrm{si}}$ to arrive at certain fundamental conclusions regarding the relative importance of low reserve pools, exploration incentives, etc. Due to the radical change to conditions these may no longer be valid and for this reason should be re-examined.

The discovery of prolific oil pools would, under any scheme of proration considered in this report, tend to reduce the allowable of at least some of the already producing wells unless there was a corresponding increase in markets. However, the adverse effect upon completed wells, will be greatest under a reserves type proration formula since every increase in reserves will proportionately decrease the allowable of every other well in the Province unless market conditions increase correspondingly. Assuming that the reserves of Alberta double in the next few years and market conditions increase normally, it is apparent that the new discoveries will usurp about one-half of the Provincial demand since proration to these pools will for all practical purposes be on the

i8 In March, 1965, Banff Oll Limited discovered oll in the well Banff Mobil Rainbow. 7-32-109-8 (W6)

io This estimate is based on the figures published by the Oil and Gas Conservation Board in the report entitled Reserves of Crude Oil Gas, Natural Gas Liquids and Sulphur-Province of Alberta, (Dec. 31, 1966) Oll and Gas Conservation Board Report 67-18.

Ro Supra, n. 2, at 29-30. 
basis of ultimate reserves; whereas for the older pools the prorationing factor will have been reduced due to significant production from the pools. It will also mean, and this is probably the most important consequence, that a much greater proportion of the Province's oil pools will fall into the low reserve category. Hence a greater number of wells will be restricted to producing on the basis of a floor allowance or slightly more. Using Figure 2 of the Board's Report ${ }^{\$ 1}$ as a guide, it is conceivable that when the scheme is fully implemented more than one-half of the Province's wells completed prior to the recent discoveries in northern Alberta will be restricted to marginal production based on the floor allowance. When it is realized that pools in fields considered prolific at one time could fall into this category, it becomes apparent that the scheme may not be entirely consistent with "allocation being made on a reasonable basis to avoid undue discrimination". There is no logic in permitting operators of the prolific pools to reap enormous profits on their investments, while restricting the remainder to marginal production, particularly since the latter have contributed greatly to the development of the Province's oil resources. It is therefore possible that the recent increase to reserves may have created an imbalance with respect to the wells that were intended to be restricted to production at the floor allowance, and for this reason a review of the matter would appear in order.

\section{H. CONCLUSIONS}

The concept of proration which has been developed in North America has two fundamental purposes; firstly, it must be designed to prevent waste, and secondly, it must protect the correlative rights of the owners of the petroleum resources in the proration jurisdiction. As is illustrated by the various schemes in use in the United States and in Canada, there is no prescribed scheme which alone will fulfill these requirements. However, all proration schemes have common principles upon which they must be based in order to fulfill the two fundamental purposes for which they were designed. In deciding upon the 1964 proration plan for Alberta, the Board, while introducing a fresh approach to the proration concept, considered either directly or indirectly virtually all fundamental aspects of a sound proration scheme. Nevertheless, like most new ideas, problems will arise upon implementation which were not otherwise foreseeable. It is at this transitional stage that the petroleum industry now finds itself with respect to the Board's new plan. It is hoped that this paper may provide some insight to the problems that may be facing the new plan in the future.

There is little doubt that it was unnecessary for the Board to change from a well to a reserves concept of prorationing in order to remedy the defects of the old scheme, and to accomplish the objectives of a proper plan. Although it may have been within the Board's prerogative under the empowering statutes, failure to justify such a change detracts from the significance of the new plan. The general consensus in industry is that major changes to proration should not be made unless absolutely necessary, and then if made, properly justified. The adoption of major changes without proper justification may be indicative of

81 Supra, n. 2. 
either the use of improper criteria in the past, or the lack of direction to the future.

Failure to provide for the recovery of drilling costs from a well's production goes to the root of a sound proration plan, from an economics, waste, and correlative rights aspect. The prevention of waste and protection of correlative rights are without question prime functions of a conservation authority, and for this reason the Board should review this aspect of its plan immediately. By providing for the recovery of drilling costs in its proration formula, the Board would also rectify some of the lesser defects of the plan. Specifically, greater participation by operators would be made possible and more incentive would be provided to explore for all of the oil resources of the Province and not merely the prolific ones.

Since the Board could not have anticipated a major increase to reserves brought about by the recent discovery of oil in the reef structures of Northern Alberta, it is important that the Board review its new plan before full implementation to ascertain whether or not certain premises made are still valid, and whether or not desired objectives will be achieved. Granted, the Board's new plan was designed to cope with changes in supply and demand, but certainly not to the extent created by the new discoveries. Whereas under the old scheme the Board was able to conclude that due to changing conditions the economic allowance concept was inappropriate, it may be that the abnormal increase to reserves has negatived some of the original objectives of the new plan. A review of the new plan in these respects would therefore appear mandatory before full implementation.

Other aspects of the new plan which could also be reviewed include the matters relating to the use of ultimate reserves as a factor in allocating the market demand to pools, accounting for the structural position of wells when distributing production among wells within a pool, and the effect on royalties of a change to the proration plan.

In conclusion, the Board's new plan is certainly an improvement from its old scheme as well as being a novel approach to proration technology. The plan in its present form is generally sound but would seem to require reconsideration before full implementation in the respects discussed. With some modifications, the plan should foster the optimum development of the conventional oil resources of the Province while prorating oil production to market demand in a "reasonable" and "equitable" manner, and without "waste". 